Bedini, L. A. (1992). Encouraging change in attitudes toward people with disabilities through undergraduate leisure

studies and recreation courses. Schole: A Journal of Leisure Studies and Recreation Education, 7, 44-54.

Made available courtesy of National Recreation and Park Association: http:/www.nrpa.org/

*** Note: This document may be reprinted and distributed for non-commercial and educational purposes only,

and not for resale: No resale use may be made of material on this web site at any time. All other rights reserved

\title{
Encouraging Change in Attitudes Toward People with Disabilities Through Undergraduate Leisure Studies and Recreation Courses
}

\author{
Leandra A. Bedini \\ University of North Carolina at Chapel Hill
}

\begin{abstract}
7 Educators in leisure studies and recreation have an obligation to enlighten students and discourage negative attitudes toward groups that traditionally experience discrimination. Research clearly demonstrates societal prejudice against people with disabilities and suggests that these biases affect and reduce the quality of life of these individuals. While college age students are capable of these prejudices, their negative attitudes can be altered. College classes can be an avenue for addressing negative attitudes toward people with disabilities. The purpose of this paper is to discuss the methods available to leisure studies and recreation educators to discourage negative attitudes toward people with disabilities. Additionally, results of a study which sought to improve attitudes toward people with disabilities by using multiple methods of instruction within a recreation course will be discussed.
\end{abstract}

\section{Biographical Information}

Dr. Bedini was a lecturer and the Director of the Personnel Preparation Training Grant at the University of North Carolina at Chapel Hill at the time this article was written. She is currently an assistant professor at the University of North Carolina at Greensboro. The author wishes to acknowledge Leigh Morris, CTRS and Lynn Hecht for their contributions to this work. Correspondence should be addressed to Dr. Bedini at: Department of Leisure Studies, 420F HHP Building, University of North CarolinaGreensboro, Greensboro, NC 27412.

People with disabilities are often treated with the same discrimination and bias as other more traditional minorities. College age students are not innocent of these prejudices. By age twenty, years of reinforcement can produce strong fears and misconceptions. Educators in the leisure studies and recreation field have a responsibility to help change these negative attitudes, and college classes can be an avenue for this change. The purpose of this paper is to discuss the methods available to educators in leisure studies and recreation to change negative attitudes about people with disabilities, and to describe a study which sought to determine the effectiveness of a multiple method approach within a recreation course to address attitude change. 


\section{Background Literature}

People with disabilities historically have experienced discrimination and devaluation based solely on being different from the non-disabled public. According to Roth (1983), it is hard for society to accept difference without ranking it and making it inferior. Schur (1980) noted that people who are different, such as those with disabilities, are placed in "devalued" categories by people in society to establish a valued status for themselves. Goffman (1963) stated that many people create their own theories to explain feelings of superiority and animosity toward those who are different. This stigmatization is often a defense used to combat anxiety created by not knowing what to do in an unfamiliar situation. Creating labels to denote variance or difference allows people to identify a category or standard response. The uncommon characteristic, therefore, becomes the identifier for the stigma (Eisenberg, Griggins, \& Duval,1982).

Negative attitudes toward people with disabilities create barriers for them. "Prevailing attitudes determine the social expectations of people and treatment accorded an individual in society" (Roeher, 1961, p. 69). Negative attitudes and fears can exclude people with disabilities from all aspects of life, even their own recreation pursuits (cf. West, 1982, 1984). Similarly, because of negative language and labeling, people with disabilities sometimes adopt the "handicapped role" which reflects social incapacitation (Dattilo \& Smith, 1990; Longmore, 1985).

\section{Attitude theory}

According to Fishbein and Ajzen (1975), attitude is a "latent underlying variable that is assumed to guide or influence behavior" (p. 8). Attitudes are formed in childhood from interactions and past experiences with the environment. They are derived from parents, playmates, teachers, literature, and media (Roeher, 1961). Fishbein (1963) proposed the theory of attitude which addressed attitude learning and the relationship between attitudes and beliefs. Fishbein's theory suggested that: (a) an individual holds many beliefs about a given object; (b) associated with each attribute is an implicit evaluation response (i.e., attitude); (c) through conditioning, evaluation responses are associated with the attitude object; (d) conditioned evaluation responses summate; and (e) on future occasions the attitude object will elicit this summated evaluation response (i.e., overall attitude). Therefore, based on Fishbein's model, conditioning can be the key to the development of new attitudes.

\section{Changing attitudes}

Gartner and Joe (1987) called for:

...a recognition of the range of humankind, the awareness that all individuals possess both strengths and limitations, ... and that 
services can best be developed which build on those strengths and address the limitations as matters to be coped with or overcome, not as defining characteristics (p. 206).

Educators have not only the responsibility but also the opportunity to be advocates for underrepresented populations such as people with disabilities and encourage the perceptions proposed by Gartner and Joe through classroom teaching. Leisure studies and recreation courses can serve as a vehicle for attitude change.

Several methods are necessary, however, for change to take place through classroom experience. Donaldson (1980) identified six techniques commonly used to change negative attitudes toward people with disabilities. They are: (a) direct or indirect (media) contact with or exposure to a person with a disability; (b) data based information about disability; (c) persuasive messages; (d) analysis of dynamics of prejudice; (e) disability simulation; and (f) group discussion.

\section{Direct contact}

Perhaps one of the most successful techniques in changing attitudes is direct contact. Yuker (1988) cited 318 comparisons from 274 research studies of the effect of contact with people with disabilities and positive attitudes. The results indicated that $51 \%$ of the studies found significant positive differences while only $10 \%$ were negative and the remaining $39 \%$ were not significant. Similarly, Hamilton and Anderson (1983), in a study of undergraduate students in a leisure studies curriculum specifically, found that an experiential-based group which had contact with people with disabilities showed significant improvements in attitudes over a control group.

Donaldson (1980) noted, however, that direct contact must be structured to make the difference. Incidental interaction will not assure positive impact (Donaldson, 1980; Towfighy-Hooshyar \& Zingle, 1984; Yuker, 1983). Equal roles between people with and without disabilities is another condition to consider when using direct contact as a technique to initiate attitude change. Makas (1988) compared people with disabilities and people without disabilities concerning what they considered to be positive attitudes toward people with disabilities. She found that there was a major discrepancy between the two groups' perceptions. People with disabilities identified behaviors such as not labelling, or promoting attitudes that defended civil and social rights of people with disabilities, as examples of positive attitudes. The people without disabilities, however, suggested that a desire to be nice and helpful was a reflection of a positive at titude toward people with disabilities, thus placing people with disabilities in a needy position, and creating an unequal relationship. Differentials of power and control such as a helper/helpee can actually create negative effects of the attitudes of the non-disabled toward people with disabilities (Donaldson, 1980; Makas, 1988). Resultant attitudes of nondisabled individuals can become sympathetic and nurturing rather than identifying the person with a disability as a social equal. Therefore, it is essential that direct contact be conducted on an equal role basis. 
Data based information.

Teaching factual information about disability is another technique for decreasing negative attitudes. According to Ibrahim and Herr (1982), increased knowledge leads to decreased negative attitudes. Factual information, lectures, and media which are often used in the classroom can affect attitudes positively (Elliott \& Byrd, 1982).

Attitude studies which used informational filmstrips as an intervention indicated not only positive changes at the time of a posttest but also positive changes weeks to one year later (Ibrahim \& Herr, 1982; Monson \& Shurtleff, 1979). These studies demonstrated what Ibrahim and Herr called "crystallization" wherein the intervention retained and perhaps increased its effects over time.

Different forms of media include props and speakers. Shortridge (1982) studied the perception of non-disabled children regarding people with disabilities after experiencing a story and orientation to equipment used by people with physical disabilities. Posttest results indicated that there was a significant positive shift in the attitudes of the non-disabled children. Austin, Powell, and Martin (1981) studied the effectiveness of a carefully planned class presentation for undergraduate recreation students using speakers with and without a disability. They found that regardless of the type of speaker, the receiving of information initiated positive change not evident in the control group.

A particular condition to note in using information to change attitudes is the frequency with which it is presented. Zajonc (1968) found that repeated exposure to a stimulus (words, pictures, etc.) could positively affect one's attitudes. Therefore, it is important to avoid mere incidental exposure to information regarding people with disabilities since it seems to have little impact in changing attitudes.

\section{Persuasive communication.}

Kennedy, Smith, and Austin (1991) described persuasive communication as a technique whereby a message is communicated with the intent of convincing the audience of its suggestions. Much classroom experience uses this technique. To be effective, however, the message must be sent by someone who is trusted or liked and the message must have strong and meaningful content. In a study using this technique, weak arguments initiated little change in attitudes of the audience (Freedman, Carlsmith, \& Sears, 1974).

\section{Analysis of prejudice.}

Perhaps the most abstract and difficult technique to implement is analysis of prejudice. This technique explores motivations and dynamics in the development and maintenance of bias and prejudicial attitudes. It is difficult to implement, however. Results of studies using this method to change attitudes toward people 
with disabilities were inconclusive regarding the ability to initiate actual change (Donaldson, 1980).

\section{Simulations.}

Simulations are common in classroom experiences that encourage students to "become" disabled for a short time The literature is mixed, however, regarding the use of this technique for changing attitudes of non-disabled individuals regarding people with disabilities. For example, Clore and Jeffrey (1972) found significant improvements in an experimental group who participated in structured simulations using wheelchairs and blindfolds while the control group demonstrated no change. These positive results lasted no longer than four months, however. Additionally, McGill (1984) cautioned that these simulations must be guided by the instructor. Accordingly, the instructor should make sure that students not only understand the purpose and procedure of the exercise, but also that they complete the entire task as designed. Additionally, the experience should be processed with the instructor's guidance and put into proper context.

\section{Group discussion.}

Few studies report the use of group discussion by itself as a technique for changing attitudes. Lazar, Orput, and Demos, (1976) used lecture, discussions, and verbal reinforcement with college students and demonstrated significant positive posttest results regarding attitudes toward people with disabilities. This technique should be used with caution as well, however. Group discussion can actually reinforce negative attitudes if not presented properly (Donaldson, 1980; Siperstein, Bak, \& Gottleib, 1977). Structure, planned discussion, and avoiding free-for-all conversations should be the focus.

Although most of the aforementioned techniques individually have generated some success in changing attitudes toward people with disabilities, the literature suggests that combinations of these methods have more potential for attitude change than applying them independently. For example, Dewar (1982) combined simulation, direct contact, and group discussion for positive results. Handlers and Austin (1981) and Jones, Sowell, Jones, and Butler (1981) combined discussion, information, simulation, and direct contact to yield significant increases in attitudes of school children toward people with disabilities. Similarly, a combination of researched information, role play, and direct contact with people with disabilities increased positive attitudes of community recreators (Stone, 1987).

According to Donaldson (1980), attitude modification requires unbalancing and unfreezing current attitudes by reducing restraining factors or increasing driving forces. In applying Fishbein's (1963) attitude theory to facilitating change of attitudes of college students through recreation courses, the key element of attitude change is the conditioning process so that old evaluation responses become unbalanced and new appropriate evaluation responses can be generated. 


\section{A Multimethod Approach to Attitude Change Applied}

The purpose of this study was to determine if a leisure studies and recreation course on recreation services for people with disabilities had a positive effect on the attitudes of college age students toward people with disabilities. The course used as the intervention was entitled, "Special Recreation Services" taught within the Curriculum in Leisure Studies and Recreation Administration (LSRA) at the University of North Carolina at Chapel Hill. This course was required for LSRA majors and was a general elective for other students. Traditionally, $80 \%$ of the students taking this class are non-majors. Information collected at the beginning of each semester regarding motivation for taking this course suggested that students enroll for reasons ranging from course requirements, to interest, to needing the hours to graduate.

The subjects consisted of 237 college age students representing over 12 majors. Female to male ratio was approximately four to one. The study's design was a pretest and posttest with control. An introductory level Journalism course $(n=51)$. made up of approximately the same types of students in terms of majors and sex, served as the control group. The LSRA course was taught by primarily one instructor ( $n=149$ over several semesters), however, the same course taught by a different instructor $(n=37)$ was included in the study to control for instructor effects. Other than the instructor, the course content, assignments, and methods were the same.

\section{Procedure}

Pretests, posttests, and followup posttests were administered to both the experimental and control groups. The pretest was given within the first three class periods of the semester. The posttest was given within the last three class periods of the semester. A followup posttest was also mailed to the students four to six months after the posttest.

The measurement instrument was The Attitudes Toward Disabled Persons (ATDP) Scale. The ATDP is a 20 question survey instrument that asks the respondent to rate his/her attitudes regarding behaviors and assumptions of people with disabilities. Responses were listed on a 6 point scale ranging from $-3=$ "I disagree very much," to a $+3=$ "I agree very much." The questions were written in the third person. For example, "Disabled people are often grouchy." Coefficient alpha reliability estimates for the ATDP scales ranged from .79 to .89 with a median of .84 . Convergent validity demonstrated high correlation with other measures of attitudes toward people with disabilities with medians ranging from .54 to .89 (Yuker \& Block,1986). 


\section{Course Content and Methods}

The content of the LSRA course which the experimental group took included a multi-unit program beginning with a unit addressing only attitudes and subsequent units on other topics. Issues about attitudes were a constant underlying theme throughout the remainder of the course. Other units covered architectural barriers, integration issues, characteristics of people with disabilities, types and settings of community recreation services to people with disabilities, programming considerations, and legislation.

The intervention for this study was a combination of teaching methods noted by Donaldson (1980) to address attitude change:

1. Direct contact was facilitated through guest speakers with disabilities as well as an assignment requiring a face to face interview with someone with a disability. The latter required a paper and both were processed thorough class discussion.

2. Information based on factual data consisted of lecture, research studies, guest lecturers from appropriate recreation settings, films, and required readings about attitudes toward people with disabilities.

3. Persuasive communication was presented within the lecture as well as later in the semester when trust could be established between the instructor and the students.

4. The analysis of prejudice was presented on a superficial level due to time constraints of the course, however, lecture did present studies about suggested causes of prejudice and how that applies to people with disabilities.

5. Students were guided in different simulations of disabilities using blindfolds and wheelchairs.

6. Large group discussion was frequently used either after an assignment was completed to process the experiences or after a speaker visited class. Additionally, small group discussions were used to explore hypothetical situations regarding attitudes toward people with disabilities.

In addition, each student had to create and complete a semester long advocacy project whereby they chose a "cause" and addressed it as an advocate. Depending on the task chosen, the students could encounter any or all of the above techniques. Examples of projects were advocating for political rights of a discriminated disability group in one's home town, or facilitating the removal of architectural barriers in one's community. Students were required to research advocacy roles and propose a project which was approved by the instructor prior to initiating it.

\section{$\underline{\text { Results }}$}

Statistical analysis consisted of descriptive statistics, $t$-tests, and analysis of variance. Analysis of variance showed no statistically significant differences ( $F$ (2, $203)=1.46, \mathrm{p}=.23$ ) among the two Leisure Studies and Recreation Administration 
(LSRA) classes $(\underline{M}=85.5$ and 82.9$)$, or the Journalism class $(\underline{M}=81.9)$ in the pretest . Additionally, $t$-tests were conducted to establish whether a significant difference existed between the two LSRA instructors. Both posttests $(\underline{t}=.85, \mathrm{p}=$ $.40)$ and followup posttests $(t=.50, p=.62)$ showed no statistical differences between the LSRA instructors suggesting uniformity in instruction.

The results of the analysis showed that students in both the LSRA courses demonstrated a statistically significant improvement between the pretest and the posttest $(\underline{t}=-8.26, \underline{p}=.000 ;$ and $\underline{t}=-.62, \underline{p}=.000$ respectively). Students in the Journalism course, however, demonstrated no statistically significant differences from pre to post tests $(\underline{t}=-.86, \underline{p}=.393)$. Further comparison of posttests through ANOVA and post hoc analysis showed that the students in the LSRA courses ( $\underline{M}$ $=95.5$ and 93.7) demonstrated statistically significantly higher scores $(F(2,216)=$ $11.98, \mathrm{p}=.000)$ than the students in the Journalism course $(\underline{M}=85.3)$.

A followup survey was conducted on the same students from the LSRA courses and the Journalism course. The students in both the LSRA classes $(\underline{M}=$ 97.4 and 95.7$)$ demonstrated statistically significantly higher scores $(F(2,150)$ $=20.16, \mathrm{p}=.000)$ in the followup than the students in the Journalism class $(\underline{\mathrm{M}}=$ 83.1).

No statistically significant difference was noted between followup posttest and posttests for either LSRA $(\mathrm{t}=-.47, \mathrm{p}=.642 ; \underline{\mathrm{t}}=-1.73, \mathrm{p}=.114)$ or Journalism $(\mathrm{t}=85, \mathrm{q}=.400)$ in either positive or negative directions. A comparison of pretest and followup testing for all groups noted a statistically significant positive difference in the students in the LSRA courses $(\underline{t}=-6.98, \underline{p}=.000 ;$ and $\underline{t}=-.387, \underline{p}=.003)$. No statistically significant changes in the Journalism class participants, however, were determined $(\underline{t}=-.97, \mathrm{p}=.339)$. See Figure 1 .

Figure 1.

Effects of multimethod intervention on attitudes toward people with disabilities.

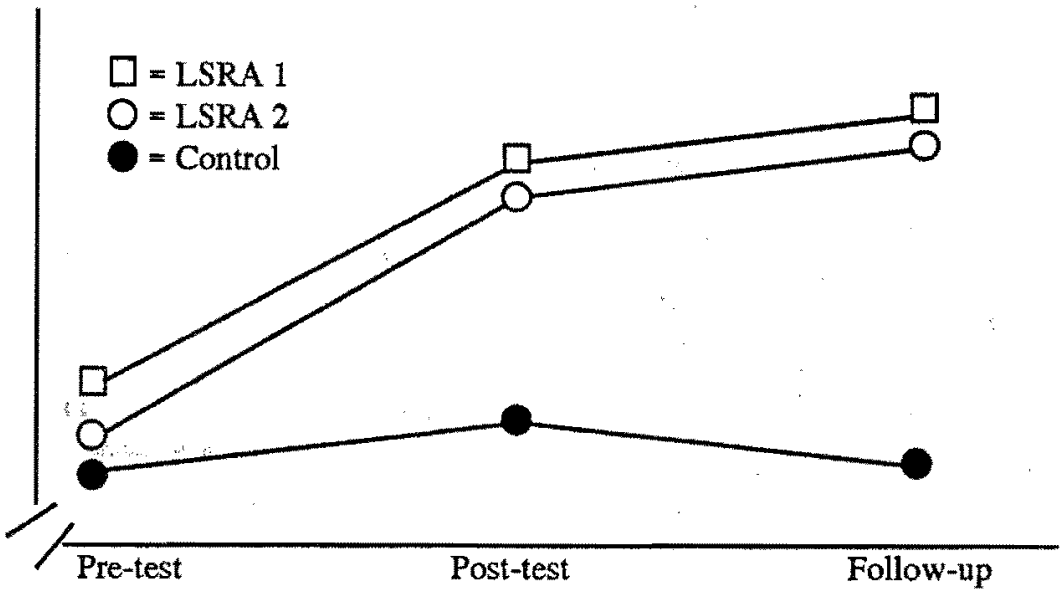




\section{Discussion}

The purpose of this study was to determine the effectiveness of a combined approach to attitude change within a recreation and leisure course. The results suggested that the LSRA course utilizing a combination of techniques had a significant positive effect on the attitudes of the students toward people with disabilities. Additionally, it seemed that for the LSRA course participants, a type of germination took place. Although there were no statistically significant differences, scores remained constant from the posttest to the followup posttest four to six months after the intervention. This result suggests crystallization of attitudes similar to the ștudies of Ibrahim and Herr (1982) and Monson and Shurtleff (1979).

The potential for long term effects on attitude change for college age students in courses like this one is strongly evident. Combination of techniques such as exposure to actual people with disabilities, experiential activities, and data based and factual education seem to have potential to unbalance one's negative attitudes allowing room for new attitudes. Although attitudes are established in one's youth, changes can occur as an adult.

Based on the literature and the results of this study, several recommendations for leisure and recreation educators exist. Leisure and recreation courses can be an appropriate environment for attitude change toward people with disabilities. Educators should evaluate their course content for inclusion of techniques that have been determined to encourage this change. The data suggest that a multimethod approach can not only improve attitudes over the course of a semester but also for several months after the intervention. Utilizing a combination of these methods seems to indicate maximum impact on the students' attitudes. Finally, to assure potential for change, educators must be cognizant of possible negative consequences of these activities if not properly facilitated and monitored. Active involvement and commitment by the educator is essential for success with these techniques.

Implications also exist from this study. First, educators should evaluate the application of a multimethod approach to initiate attitude change about other devalued groups such as people of color and women. Conceptually similar effects should result. Second, studies should be designed to evaluate the long term crystallization of positive changes in attitudes toward people with disabilities a year or more after intervention. Finally, smaller combinations of techniques should be systematically evaluated to determine their maximum strength of effectiveness.

In sum, recreation and leisure educators have great potential to facilitate change and remove negative attitudes to any discriminated population, not just people with disabilities through the use of multimethod techniques. Using these techniques and being alert to the opportunities within the classroom, leisure studies and recreation courses can become an arena for change and enlightenment. 


\section{References}

Austin, D. R. , Powell, L. G. , \& Martin, D. W. (1981). Modifying attitudes toward handicapped individuals in a classroom setting. The Journal for Special Educators, 17 (2), 135-141.

Clore, G. L., \& Jeffrey, K. M. (1972). Emotional role playing, at titude change, and attraction toward a disabled person. Journal of Personality and Social Psychology. 23, 105-111.

Dattilo, J., \& Smith, R. W. (1990). Communicating positive attitudes toward people with disabilities through sensitive terminology. Therapeutic Recreation Journal, 24 (1), 8-17.

Dewar, R. L. (1982). Peer acceptance of handicapped students. Teaching Exceptional Children, 14(5) 188-193.

Donaldson, J. (1980). Changing attitudes toward handicapped persons. A review and analysis of research. Exceptional Children, 46 (7), 504-514,

Eisenberg, M. G., Griggins, C., \& Duval, R. J. ( Eds.). (1982). Disabled people as second-class citizens. NY: Springer Publishing.

Elliott, T. R., \& Byrd, E. K (1982). Media and disability. Rehabilitation Literature, 43 (11-12), 348-355.

Fishbein, M., \& Ajzen, I. (1975). Belief, attitude, intention and behavior: An introduction to theory and research. Reading, MA: Addison-Wesley Publishing Company.

Fishbein, M. (1963). An investigation of the relationships between beliefs about an object and the attitude toward that object. Human Relations, 16, 233-240.

Freedman, J. L. , Carlsmith, J. M., \& Sears, D. O. (1974). Social psychology (2nd ed.). Englewood Cliffs, NJ: Prentice-Hall Publishing.

Gartner, A. \& Joe, T. (Eds.). (1987). Images of the disabled, disabling images. NY: Praeger.

Goffman, I. (1963). Stigma. Englewood Cliffs, NJ: Prentice Hall Publishing. Hamilton, E. J., \& Anderson, S. C. (1983). Effects of leisure activities on attitudes toward people with disabilities. Therapeutic Recreation Journal, 17 (3), 50-57.

Handlers, A., \& Austin, K (1981). Improving attitudes of high school students toward handicapped peers. Exceptional Children, 47, 228-229.

Ibrahim, F. A., \& Herr, E. L. (1982). Modification of attitudes toward disability:

Differential effect of two education modes. Rehabilitation Counseling Bulletin, 26 (1), 29-36.

Jones, T. W., Sowell, V. M., Jones, J. K., \& Butler, L. G. (1981). Changing children's perceptions of handicapped people. Exceptional Children. 47, 365-368.

Kennedy, D., Smith, R. W., \& Austin, D. (1991). Special recreation: Opportunities for persons with disabilities (2nd ed.). Dubuque, IA: Wm C. Brown, Publishers.

Lazar, A L., Orput, R., \& Demos, G. (1976). The impact of class instruction on changing student attitudes. Rehabilitation Counseling Bulletin, 20, 66-68.

Longmore, P. K. (1985). A note on language and the social identity of disabled people. American Behavioral Scientist, 28, 419-423. 
Makas, E. (1988). Positive attitudes toward disabled people: disabled and nondisabled persons' perspectives. Journal of Social Issues, 44 (1), 49-61.

McGill, J. (1984). Training for integration: Are blindfolds really enough?

Leisurability, 11(2), 12-15.

Monson, D., \& Shurtleff, C. (1979). Altering attitudes toward the physically handicapped through print and non-print media. Language Arts, 56 (2), 163-170.

Roeher, G. A. (1961). Significance of public attitudes in the rehabilitation of the disabled. Rehabilitation Literature, 22 (3), 68-74.

Roth, W. (1983). Handicap as a social construct. Society, 2, 56-61.

Schur, E. M. (1980). The politics of deviance. Englewood Cliffs, NJ: Prentice Hall Publishing.

Shortridge, S. D. (1982). Facilitating attitude change toward the handicapped. The American Journal of Occupational Therapy, 36 (7), 456-461.

Siperstein, G. N., Bak, J. J., \& Gottleib, J. (1977). Effects of group discussions on children's attitudes toward handicapped peers. Journal of Educational Research, 70, 131-134.

Stone, C. F. (1987). Examining attitudes of non-disabled individuals toward disabled individuals though use of L. I. F. E. inservice training. Unpublished manuscript, University of North Carolina at Chapel Hill.

Towfighy-Hooshyar, N., \& Zingle, H. W. (1984). Regular class students' attitudes toward integrated multi handicapped peers. American Journal of Mental Deficiency, 88, 630-637.

West, P. C. (1982). Organizational stigma in metropolitan park and recreation agencies. Therapeutic Recreation Journal, 16 (4), 35-41.

West, P. C. (1984). Social stigma and community recreation participation by the mentally and physically handicapped. Therapeutic Recreation Journal, 18 (1), 40-49.

Yuker, H. E. (1983). The lack of stable order of preference for disabilities: A response to Richardson and Ronald. Rehabilitation Psychology, 28, 93-103. Yuker, H. E. (1988). The effects of contact on attitudes toward disabled persons: Some empirical generalizations. In H. E. Yuker, (Ed.). Attitudes toward people with disabilities (pp. 262-274). NY: Springer Publishing.

Yuker, H. E., \& Block, J. R. (1986), Research with attitudes toward disabled persons scales 1960-1985. Hemstead, NY: Hofstra University Center for the Study of Attitudes Toward Disabled Persons.

Zajonc, R. B. (1968). Attitudinal effects of mere exposure. Journal of Personality and Social Psychology, 9 (2), 1-27. 